\title{
Remoção da cartilagem articular associada ou não a implante homógeno ou enxerto autógeno de osso esponjoso em cães submetidos à artrodese atlantoaxial
}

\author{
Joint cartilage removal associated or not to homologous implant or autologous cancellous bone \\ graft in dogs submitted to atlantoaxial arthrodesis
}

\author{
Rafael Festugatto ${ }^{\mathrm{I}}$ Alexandre Mazzanti ${ }^{\mathrm{I}^{*}}$ Alceu Gaspar Raiser ${ }^{\mathrm{II}}$ Fernanda Souza Barbosa da Silva ${ }^{\mathrm{I}}$

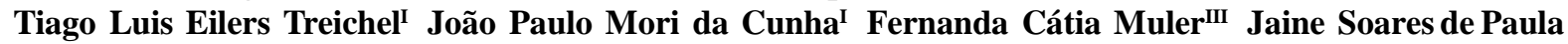 \\ Vasconcellos $^{\text {III }}$ Denise de Castro Veiga ${ }^{\text {IV }}$ Bruno Leite dos Anjos $^{\mathrm{V}}$
}

\section{RESUMO}

O objetivo deste estudo foi avaliar o grau de fusão articular e formação óssea na articulação atlantoaxial de cães submetidos à artrodese após a remoção da cartilagem articular associada ou não ao implante homógeno ou enxerto autógeno de osso esponjoso. Foram utilizados 12 cães, adultos, distribuídos aleatoriamente em três grupos iguais. Grupo I (GI): realizada apenas a remoção da cartilagem articular e imobilização articular com pinos e resina acrílica. Grupo II (GII): feita a remoção da cartilagem articular e imobilização da articulação, seguida da colocação e modelagem do implante ósseo esponjoso homógeno entre as superfícies articulares. Grupo III (GIII): foi realizado o mesmo procedimento do GII, mais o enxerto ósseo esponjoso autógeno no local determinado. Realizaram-se exames radiográficos em todos os animais aos 30, 60 e 90 dias de pós-operatório (PO). Aos 90 dias de PO foi feita a eutanásia para o emprego do teste de palpação manual, avaliação tomográfica e histopatológica. Para análise estatística da associação entre o grau de fusão articular, aplicou-se o Teste Qui-quadrado de independência. Os resultados dos testes foram avaliados pela significância exata e considerados significantes a $5 \%(P<0,05)$. Pelo teste de palpação manual e pelas imagens tomográficas, não houve diferença entre os grupos aos 90 dias de PO. A análise radiográfica da articulação atlantoaxial mostrou que o grau de fusão era semelhante entre os tratamentos entre os tempos de evolução. Com relação ao estudo histopatológico da articulação atlantoaxial dos cães, decorridos 90 dias de $P O$, foi verificado que a proliferação óssea no grupo I apresentou grau de intensidade proporcional, no grupo II, $75 \%$ leve e $25 \%$ acentuada e, no grupo III, $25 \%$ moderada e

\begin{abstract}
$75 \%$ acentuada. Não existe diferença quanto ao grau de fusão articular e formação óssea quando a técnica de artrodese atlantoaxial em cães for associada ao enxerto de osso esponjoso autógeno ou implante homógeno. A remoção da cartilagem articular isoladamente é uma alternativa eficiente e apresenta resultados semelhantes, quando associada ao enxerto autógeno ou implante homógeno.
\end{abstract}

Palavras-chave: artrodese atlantoaxial, osso homógeno, neurologia, cão.

\section{ABSTRACT}

The aim of this study was to evaluate the degree of joint fusion and bone formation in dogs undergoing atlantoaxial arthrodesis after removal of articular cartilage associated or not to implant homogenous or autogenous cancellous bone. Twelve dogs, weighing between 8 and $12 \mathrm{~kg}$ were randomly divided into three groups. Group I (GI) performed only the removal of joint cartilage and joint immobilization with acrylic resin and pins. Group II (GII): after removel of joint cartilage and articular immobilization was performed modeling and placement of homogenous cancellous bone at the given location. The volume of homograft placed in the joint was measured using a precision balance and all animals received the same amount. Group III (GIII): this was the same procedure as GI, however, was used autogenous cancellous bone graft at the given location. Radiographic examinations were performed on all animals at 30, 60 and 90 days postoperatively. At 90 days of $P O$ was carried out euthanasia of animals for testing of manual palpation and CT evaluation and histological. Samples were

IPrograma de Pós-graduação em Medicina Veterinária, Centro de Ciências Rurais (CCR),Universidade Federal de Santa Maria (UFSM), Santa Maria, RS, Brasil.

"Departamento de Clínica de Pequenos Animais (DCPA), CCR, UFSM, Santa Maria, RS, Brasil. E-mail: alexamazza@yahoo.com.br. *Autor para correspondência.

"IC Curso de Medicina Veterinária, UFSM, Santa Maria, RS, Brasil

${ }^{\mathrm{I}}$ Universidade da Região da Campanha (URCAMP), Alegrete, RS, Brasil.

vUniversidade Federal do Pampa (UNIPAMPA), Uruguaiana, RS, Brasil. 
kept in solution in $10 \%$ buffered formaldehyde for fixation for a minimum of 72 hours and after, decalcified in formic acid and sodium citrate for subsequent processing and included in paraffin. Sections were stained with hematoxylin-eosin for light microscopy evaluation. Statistical analysis of the association between the degree of joint fusion assessed by manual palpation, the digitized radiographic images and CT scans and treatment groups, we applied the Chi-square test of independence. The test results were evaluated by the exact significance and considered statistically significant at 5\% significance $(P<0.05)$. By manual palpation test and by the CT images can be seen that there was no statistically significant difference between groups at 90 days postoperatively. Radiographic analysis of the atlantoaxial joint showed that the degree of fusion was similar among treatments, no statistical difference at 30, 60 and 90 days postoperatively. Regarding the histopathological study of atlantoaxial joint of dogs after 90 days postoperatively was found that bone formation in group I had 25\% of each intensity (absent, mild, moderate, severe) in group II, 75\% lighter and 25\% sharp and in group III, 25\% moderate and $75 \%$ severe. It can be concluded that the use of graft homogenous preserved in $98 \%$ glycerin in dogs undergoing atlantoaxial fusion method is a viable alternative for treatment of atlantoaxial instability. There is no difference in the degree of joint fusion and bone formation when the technique of atlantoaxial arthrodesis in dogs is associated with autogenous cancellous bone graft or implant homogenous. The removal of articular cartilage alone is an effective and shows similar results to the use of autograft or homogenous implant.

Key words: atlantoaxial instability, cancellous bone, neurology, dog.

\section{INTRODUÇÃO}

Em cães, o tratamento cirúrgico para a instabilidade atlantoaxial (IAA) inclui diferentes técnicas de estabilização dorsal ou ventral. As complicações na fixação ventral são menos comuns do que no acesso dorsal (SHARP \& WHEELER, 2005) e os resultados de diversos trabalhos sugerem que a estabilização da articulação atlantoaxial pela abordagem ventral possa ser mais segura do que a dorsal (THOMAS et al., 1991), pois possibilita a remoção da superfície articular entre o atlas e o áxis, o que poderia acelerar o processo de fusão (SCHULZ et al., 1997).

Durante os procedimentos de fusão articular, utiliza-se o enxerto autógeno (EA) esponjoso (THOMAS et al., 1991; SCHULZ et al., 1997; SHIRES, 1998; PLATT et al., 2004; DEWEY, 2006; LORENZ \& KORNEGAY, 2006; SHORES \& TEPPER, 2007) para estimular a consolidação (HERBERT et al., 1998) o que, conforme DRESPE et al. (2005), é crucial para o sucesso do procedimento.

Porém, muitas vezes, a retirada do enxerto autógeno pode produzir efeitos indesejados no animal, como dor e infecção no sítio doador (SANADA et al., 2003; SILVA et al., 2010), aumento do tempo de intervenção e a quantidade de enxerto obtida pode não ser suficiente (PIERMATTEI \& FLO, 1999). Por essas razões, há muito interesse em desenvolver materiais alternativos para o enxerto ósseo autógeno (DRESPE et al., 2005), além da necessidade do desenvolvimento de técnicas de estocagem e preservação de osso esponjoso, constituindo bancos, facilmente criados com o uso de osso proveniente de doadores cadáveres (VOLPON \& DACOSTA, 2000).

O objetivo deste trabalho foi avaliar o grau de fusão articular e formação óssea na articulação atlantoaxial de cães submetidos à artrodese após a remoção da cartilagem articular, associada ou não ao enxerto autógeno ou implante homógeno de osso esponjoso, conservado em glicerina a $98 \%$.

\section{MATERIAL E MÉTODOS}

Foram utilizados 12 cães adultos, independente do sexo, sem raça definida, com idade média de quatro anos e peso médio de $10 \mathrm{~kg}$, alojados em baias individuais por um período mínimo de 15 dias, para adaptação ao local, quando receberam ração e água ad libidum. Os cães receberam duas doses de vermífugo a base de pamoato de pirantel e praziquantel ( $25 \mathrm{mg} \mathrm{kg}^{-1}$ ) em um intervalo de 15 dias.

Os cães foram distribuídos aleatoriamente em três grupos de igual número: grupo I (GI) - realizada apenas a remoção da cartilagem articular (RCA) e imobilização articular com pinos e resina acrílica; grupo II (GII) - após a remoção da cartilagem articular e imobilização da articulação, era colocado e modelado implante ósseo esponjoso homógeno no espaço articular (200mg no espaço e $300 \mathrm{mg}$ ao redor determinado por balança de precisão); grupo III (GIII) realizado procedimento idêntico ao GII, no entanto, foi utilizado enxerto ósseo esponjoso autógeno.

O osso esponjoso foi coletado da região do tubérculo maior do úmero de cadáveres caninos sob método higiênico, mas não asséptico. Após a coleta, o osso esponjoso homógeno foi colocado em uma cuba, higienizado com solução salina isotônica estéril e conservado em frascos estéreis previamente identificados, contendo glicerina a $98 \%$ PA em temperatura ambiente, por um período mínimo de 30 dias, sendo a glicerina trocada decorridos dois dias de conservação.

Após jejum hídrico de 12 horas, os animais receberam sulfato de morfina $\left(0,7 \mathrm{mg} \mathrm{kg}^{-1}\right)$, associada, na mesma seringa, à acepromazina $\left(0,05 \mathrm{mg} \mathrm{kg}^{-1}\right)$ intramuscular, seguida de indução anestésica com propofol (5,0mg kg-1, IV) e mantidos sob anestesia inalatória com isofluorano. A analgesia trans-operatória foi assegurada com o uso de fentanil $\left(0,002 \mathrm{mg} \mathrm{kg}^{-1}, \mathrm{IV}\right)$ 
e realizado antibiótico profilático com cefalotina sódica (30 $\left.\mathrm{mg} \mathrm{kg}^{-1}, \mathrm{IV}\right), 30$ minutos antes do início da intervenção cirúrgica.

A contenção, abordagem cirúrgica e imobilização em cada animal foi a mesma descrita por FESTUGATTO et al. (2009). Exposta a articulação, foi realizada a remoção da cartilagem articular com auxílio de broca sulcada de $4 \mathrm{~mm}$, acoplada à perfuratriz elétrica de baixa rotação, até a visualização do osso subcondral. Para estabilização da articulação atlantoaxial, foram utilizados dois pinos de Steimann, associados à resina acrílica autopolimerizável, conforme técnica descrita por SHARP \& WHEELER (2005).

Nos animais do grupo II, o implante foi removido do frasco de conservação e lavado com solução de cloreto de sódio $0,9 \%$ (SS), com auxílio de seringa acoplada à agulha hipodérmica $25 \times 8$. $\mathrm{O}$ osso esponjoso permaneceu por 10 minutos em uma cuba rim estéril, contendo SS e era disposto em uma gaze embebida em sangue do campo operatório do receptor. Em seguida, realizou-se a pesagem e posicionou-se o osso no local determinado.

Nos animais do grupo III, a colheita do osso esponjoso foi feita de forma semelhante ao acesso descrito para obtenção e conservação do implante, porém, após a preparação da articulação atlantoaxial, o enxerto era pesado e aplicado no local determinado.

A síntese do músculo longo do pescoço foi realizada com fio poliglactina 910 número 3-0 em um padrão de sutura contínua simples. Aproximaram-se os músculos esternohioideos e o tecido subcutâneo com fio poliglactina 910 em padrão contínuo simples e a pele com fio mononáilon 4-0 em pontos de Wolff. Os animais receberam terapia anti-inflamatória de meloxicam $(0,2 \mathrm{mg}$ $\mathrm{kg}^{-1}, \mathrm{IM}$, por três dias) e sulfato de morfina $\left(0,3 \mathrm{mg} \mathrm{kg}^{-1}\right.$, via subcutânea, $6 / 6$ horas, por 48 horas).

Os animais foram avaliados por teste de palpação manual (TPM), radiografia simples (RS), tomografia computadorizada (TC) e por estudos histopatológicos. O TPM no segmento cervical, submetido à artrodese era realizado imediatamente após a eutanásia (realizada com administração de tiopental sódico [IV] e, após a ausência do reflexo corneal, aplicação de cloreto de potássio [IV]). Cada segmento, desprovido dos pinos e de tecidos moles, foi manipulado por dois avaliadores que não sabiam qual tratamento o animal recebeu. A articulação era avaliada como grau 2 - quando rígida e ausência de movimentação, grau 1 - reduzida mobilidade articular rotacional, grau 0 - movimento articular rotacional típico, conforme LIPPMAN et al. (2004). Após realização do TPM, as amostras foram mantidas em solução de formaldeído tamponado a $10 \%$.
Os exames radiográficos simples eram realizados em todos os animais aos 30,60 e 90 dias após o procedimento cirúrgico, nas incidências ventrodorsal e látero-lateral. As radiografias foram submetidas a um processo de digitalização através de câmera digital e armazenadas no formato JPEG, representando as imagens originais. As imagens digitalizadas eram interpretadas por dois radiologistas que não tinham conhecimento a qual grupo o animal pertencia. Para a quantificação radiográfica do grau de fusão atlantoaxial, os observadores utilizaram uma graduação de zero a três, modificados de COOK et al. (2004): grau 0 nenhuma formação óssea; grau 1 - formação óssea mínima; grau 2 - formação óssea com fusão parcial; grau 3 - formação óssea com fusão completa. Foram avaliados separadamente os dois lados da articulação, sendo que o processo odontoide do áxis foi eleito como ponto central.

A tomografia computadorizada (TC) do segmento cervical foi realizada para detecção de fusão da articulação atlantoaxial. $\mathrm{O}$ aparelho utilizado foi modelo helicoidal GE Healthcare, seguindo os seguintes parâmetros: $16,2 \mathrm{cmDFOV}, 130 \mathrm{Kv}, 80 \mathrm{~mA}, 1 \mathrm{~mm}$ gap, $1 \mathrm{~mm}$ slice, plano coronal e filtro para osso. Utilizou-se uma escala de graduação de fusão adaptada de GUPTA et al. (2007), que varia de 0 a 4: 0 = sem formação óssea; 1 = formação óssea unilateral, mas sem fusão; 2 = formação óssea bilateral, mas sem fusão; 3 = fusão unilateral; 4 = fusão bilateral.

Para histologia, as amostras foram descalcificadas em ácido fórmico e citrato de sódio para posterior processamento e inclusão em parafina. Os cortes histológicos foram corados com hematoxilinaeosina, para avaliação em microscopia ótica. $\mathrm{Na}$ análise microscópica, avaliou-se quantitativamente ([-] ausente, $[+]$ leve, $[++]$ moderada, $[+++]$ acentuada) a ocorrência de neoformação óssea.

Para análise estatística da associação entre o grau de fusão articular, avaliado por palpação manual, das imagens radiográficas digitalizadas e tomográficas e os grupos de tratamento, aplicou-se o Teste Quiquadrado de independência. Para análise estatística da associação entre o grau de fusão articular, avaliado pela histologia, aplicou-se o teste Kruskal-Wallis. Os resultados dos testes foram avaliados com nível de significância de 5\%.

Foi realizado o teste Kappa (FLEISS, 1973) para avaliar o grau de concordância entre os avaliadores. Os valores obtidos foram classificados de acordo com a escala modificada de LANDIS \& KOCH (1977): (0$0,20)$ pobre; $(0,21-040)$ regular; $(0,41-0,60)$ moderado; $(0,61-0,80)$ bom; $(0,81-0,99)$ excelente e $1,00=$ perfeito 


\section{RESULTADOS E DISCUSSÃO}

Todos os animais toleraram o procedimento e deambularam imediatamente após a recuperação anestésica. Nenhuma complicação ou infecção relacionada à ferida cirúrgica foi observada. Em cinco cães, foi verificado edema na face ventral do pescoço, mas regrediu no sétimo dia de PO. Isso provavelmente ocorreu pela manipulação dos tecidos e da localização cirúrgica ventral, que favorecem o acúmulo de líquidos no espaço intersticial. Todos os cães do grupo III, ou seja, que receberam enxerto de osso esponjoso autógeno apresentaram claudicação do membro torácico direito no pós-operatório (PO) imediato, devido ser o local de colheita, mas que regrediu entre o segundo e terceiro dia de PO.

No teste de palpação manual, aos 90 dias de PO, duas das quatro amostras dos grupos I e II foram classificadas como grau 2 (rígida, ausência de movimentação) e as outras duas apresentaram reduzida mobilidade articular rotacional (grau 1). No grupo III, três amostras receberam grau $2 \mathrm{e}$ a outra recebeu grau 1 de um avaliador e grau 2 do outro. Não houve diferença entre os tratamentos e o valor do coeficiente Kappa observado foi de 0,824, estatisticamente significante $(\mathrm{P}<0,05)$, indicando um nível excelente de concordância entre os examinadores.

Pode-se perceber, pela análise radiográfica da articulação atlantoaxial, que o grau de fusão foi semelhante entre os grupos, não havendo diferença entre os tratamentos nos diferentes tempos de $\mathrm{PO}$ $(\mathrm{P}<0,05)$. Aos 90 dias de PO, no lado esquerdo, um animal do GI apresentou formação óssea com fusão completa, outros dois, formação óssea com fusão parcial e um com formação óssea mínima. No GII, três animais apresentaram formação óssea com fusão parcial e o outro, nenhuma formação óssea. Três animais do grupo GIII apresentaram formação óssea com fusão parcial e um apresentou formação óssea mínima (avaliador 1) ou formação óssea com fusão parcial (avaliador 2). No lado direito, um animal do GI apresentou formação óssea com fusão completa, um apresentou formação óssea com fusão parcial, um com formação óssea mínima e o outro demonstrou formação óssea mínima (avaliador 1) ou formação óssea com fusão parcial (avaliador 2). No GII, três animais demonstraram formação óssea com fusão parcial e um, formação óssea mínima. Dois animais do GIII com formação óssea com fusão parcial e outros dois formação óssea mínima (Figura 1). O coeficiente Kappa observado aos 30 e 60 dias de PO foi 1,000, indicando um nível perfeito de concordância. Aos 90 dias de PO, o nível de concordância foi excelente $(0,824)$.
Os graus de fusão detectados pela tomografia computadorizada foram semelhantes aos da avaliação radiográfica, sem diferença entre os grupos. No GI, um animal apresentou fusão no lado esquerdo e formação óssea, mas sem fusão no lado direito, os outros três animais apresentaram formação óssea bilateral sem fusão. No GII, um animal apresentou formação óssea unilateral, mas sem fusão no lado esquerdo e o lado direito sem formação óssea, os demais apresentaram formação óssea bilateral, mas sem fusão. No GIII, um animal apresentou formação óssea, mas sem fusão no lado esquerdo e o lado direito sem formação óssea, dois animais apresentaram formação óssea bilateral, mas sem fusão e o outro mostrou fusão no lado esquerdo e formação óssea, mas sem fusão no lado direito (Figuras 1A, 1B, 1C, 1D e 1F).

Conforme STEVENSON (1990), o enxerto autógeno de osso esponjoso promove fusão óssea superior a qualquer outro tipo de aloimplante. Diversos autores propõem a sua utilização durante o procedimento de fusão da articulação atlantoaxial (PLATT et al., 2004; OLBY \& PLATT, 2004; DEWEY, 2006; LORENZ \& KORNEGAY, 2006; SHORES \& TEPPER, 2007) para estimular a consolidação (HERBERT et al., 1998) e, conforme DRESPE et al. (2005), é crucial para o sucesso do procedimento, pois contribui ativamente na osteogênese por meio de células que sobrevivem ao transplante (ALEXANDER, 1987), é rapidamente incorporado pelo receptor e não possui diferença quanto à histocompatibilidade (MARTINEZ \& WALKER, 1999). No entanto, os achados do presente experimento mostram que o osso esponjoso homógeno apresenta resultados semelhantes ao enxerto autógeno quanto ao grau de fusão articular.

Os animais do grupo I apresentaram resultados semelhantes aos demais grupos e não tiveram complicações no PO, como as ocorridas no estudo de JESEREVICS et al. (2008). Esses autores utilizaram o acesso ventral para estabilização da articulação atlantoaxial com parafusos corticais em dez cães, sem utilizar enxerto autógeno e sem remoção da cartilagem articular, e seis deles tiveram migração dos implantes por instabilidade articular. Conforme SCHULZet al. (1997), a remoção da superfície articular entre o atlas e o áxis pode acelerar o processo de fusão e consequente a estabilização articular, o que, juntamente com a resina acrílica autopolimerizável, provavelmente, tenha colaborado para a ausência de migração dos implantes nos 12 animais do presente estudo.

Das 12 amostras, duas foram consideradas completamente fusionadas (GI) pela radiografia simples, 


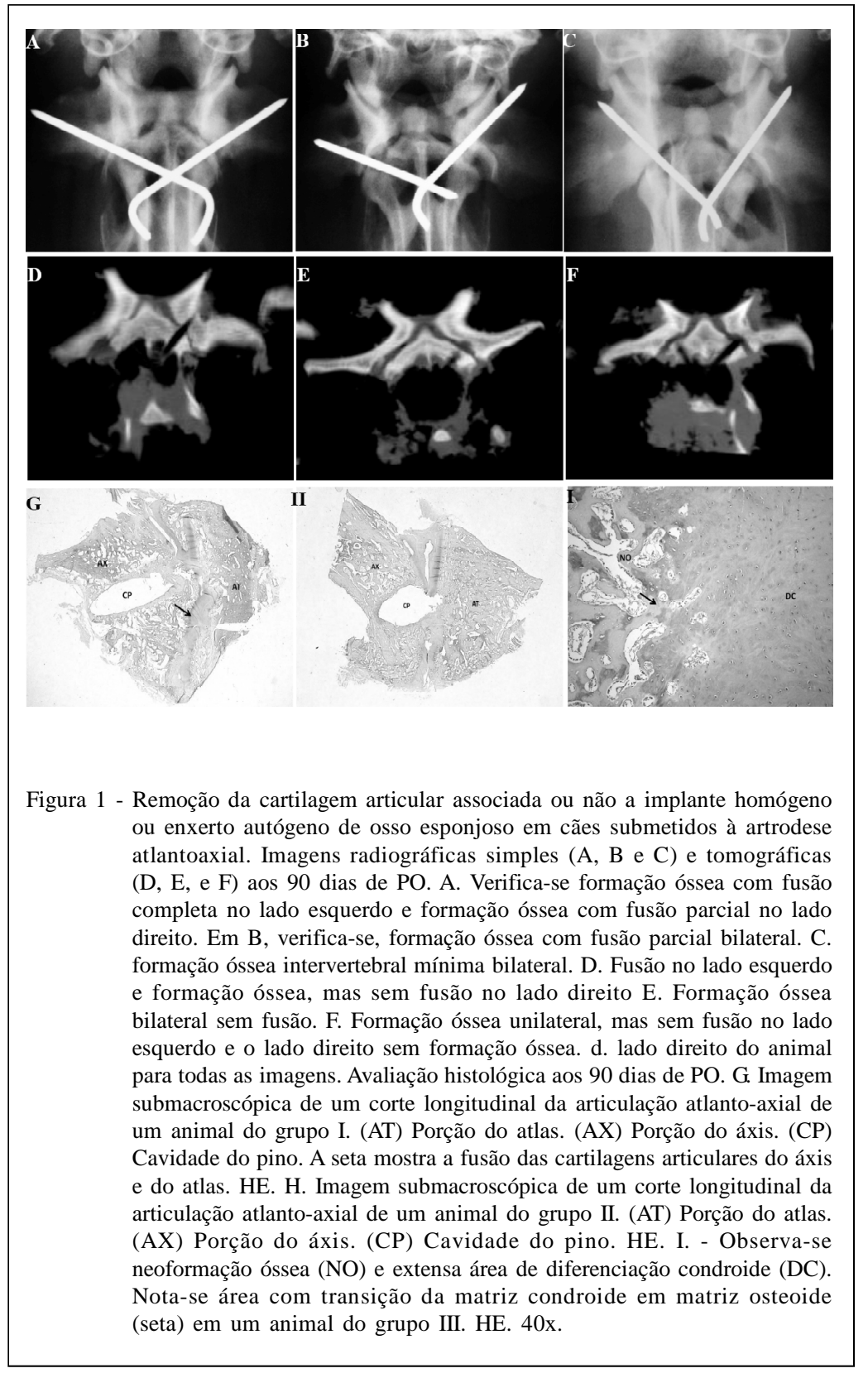

e duas pela tomografia computadorizada (uma do GI e outra do GIII), no entanto, o teste de palpação manual revelou sete amostras com possível fusão. Considerase o TPM como o mais importante para detecção de fusão intervertebral atualmente, corroborando DRESPE et al. (2005) e utilizado por WHEELER et al. (2007), BRANSFORD et al. (2007), MINAMIDE et al. (2007) e O'LOUGHLIN et al. (2009).

SORJONEM \& SHIRES (1981) estudaram 18 animais submetidos à artrodese atlantoaxial pelo acesso ventral com remoção da cartilagem articular e utilização de enxerto autógeno e que sofreram eutanásia na sexta semana de PO. Os autores citam que, nesse período, na avaliação radiográfica, três animais apresentaram evidência de fusão da articulação, confinada às bordas mediais e laterais. No entanto, no TPM, dez amostras foram consideradas fusionadas, classificadas como rígidas ou firmes.

Para MING YEE et al. (2004), vários métodos de avaliação de fusão estão em desenvolvimento e alguns estudos têm questionado a validade das radiografias simples em determinar a fusão intervertebral (CHRISTENSEN et al., 2001; COOK et al., 2004). BLUMENTHAL \& GILL (1993) compararam 
a avaliação radiográfica simples com o teste de palpação manual e concluíram que a radiografia simples pode subestimar o grau de fusão em um osteoide prémineralizado, que pode estar funcionalmente fusionado, mas ainda não apresenta radiopacidade, o que provavelmente ocorreu nas cinco outras amostras da presente pesquisa. SCHULZ et al. (1997) citam que a presença da resina acrílica autopolimerizável dificulta a avaliação radiográfica da progressão da artrodese.

Conforme BARAMKI et al. (2000), a TC é mais sensível e específica que a radiografia simples e tem sido usada por diversos autores (GUPTA et al., 2007; CANAVESE et al., 2007; LEE et al., 2008; CARTER et al., 2009) para detecção de fusão intervertebral. Porém, COOK et al. (2004), ao comparar as avaliações radiográfica e tomográfica com a histológica, concluíram que a TC é superior à radiografia simples para detectar a fusão intervertebral, no entanto, foi ineficaz em determinar a extensão da fusão óssea presente e confirmada na histologia, destacando também a superioridade do TPM sobre os demais exames.

Quanto ao estudo histopatológico da articulação atlantoaxial, decorridos 90 dias de PO, foi verificado, em relação à atividade osteoclástica e proliferação de vasos sanguíneos, $75 \%$ de intensidade leve e $25 \%$ moderada no grupo I, $25 \%$ de intensidade leve, $25 \%$ moderada e $50 \%$ acentuada no grupo II e $75 \%$ leve e $25 \%$ acentuada no grupo III, não havendo diferença entre os grupos. A maior percentagem de atividade osteoclástica no grupo II possivelmente ocorreu pela presença do implante homógeno. MAZZANTI et al. (2004) também verificaram osteoclastos ao redor da patela implantada na $8^{\mathrm{a}}$ semana de pós-operatório e atribuiu o achado a um processo de reabsorção. Quanto à neoformação óssea, o grupo I apresentou $25 \%$ de cada intensidade (ausente, leve, moderada, acentuada), no grupo II, $75 \%$ leve e $25 \%$ acentuada e no grupo III, $25 \%$ moderada e $75 \%$ acentuada, não havendo diferença entre os tratamentos $(\mathrm{P}<0,05)$. Como era esperado e corroborando WHEELER et al. (2007), a incorporação do enxerto autógeno foi superior, com excelente integração óssea. No entanto, com exceção de um animal, todos os demais dos grupos I e II apresentaram características histopatológicas semelhantes, com formação óssea (Figuras 1G, 1H e 1I). COOK et al. (2001) utilizaram enxerto de osso esponjoso na fusão espinhal em cães e observaram evidências de fusão histológica definida como nova formação óssea e remodelação do enxerto, semelhante ao encontrado na atual pesquisa. De forma geral, as características histológicas encontradas nos animais do grupo I não diferem dos demais grupos.

\section{CONCLUSÃO}

Pelos resultados obtidos e modelo experimental proposto, conclui-se que não existe diferença quanto ao grau de fusão articular e formação óssea quando a técnica de artrodese atlantoaxial em cães for associada ao enxerto de osso esponjoso autógeno ou implante homógeno. A remoção da cartilagem articular isoladamente é uma alternativa eficiente e apresenta resultados semelhantes, quando associada ao uso de enxerto autógeno ou implante homógeno.

\section{AGRADECIMENTO}

Ao Conselho Nacional de Desenvolvimento Científico e Tecnológico, pela concessão de bolsa a autora Jaine Soares de Paula Vasconcellos, bolsista de iniciação, processo 508786/2010-0.

\section{COMITÊ DE ÉTICA E BIOSSEGURANÇA}

Este estudo foi aprovado pelo Comitê de Ética em Pesquisa com animais da Universidade Federal de Santa Maria, sob o no 014/2011.

\section{REFERÊNCIAS}

ALEXANDER, J.W. Bone grafting. Veterinary Clinics of North America: Small Animal Practice, v.17, n.4, p.811-819, 1987.

BARAMKI, H.G. et al. The efficacy of interconnected porous hydroxyapatite in achieving posterolateral lumbar_fusion in sheep. Spine, v.25, p.1053-1060, 2000. Disponível em: <http:/ /journals.1ww.com/spinejournal/pages/articleviewer.aspx? year $=2000 \&$ issue $=05010 \&$ article $=00003 \&$ type $=$ abstract $>$. Acesso em: 22 nov. 2011.

BLUMENTHAL, S.L.; GILL, K. Can lumbar spine radiographs accurately determine fusion in postoperative patients? Correlation of routine radiographs with a second surgical look at lumbar fusions. Spine, v.18, p.1186-1189, 1993.

BRANSFORD, R. et al. Effect of zoledronic acid in an L6-L7 rabbit spine fusion model. Europe Spine Journal, v.16, p.557562, 2007. Disponível em: <http://www.ncbi.nlm.nih.gov/pmc/ articles/PMC2229826/pdf/586_2006_Article_212.pdf>. Acesso em: 22 agosto. 2011. doi: 10.1007/s00586-006-0212-y.

CANAVESE, F. et al. Dorsal arthrodesis of thoracic spine and effects on thorax growth in prepubertal New Zealand white rabbits. Spine, v.32, n.16, p.443-450, 2007. Disponível em: <http://www.ncbi.nlm.nih.gov/pmc/articles/PMC2822414/>. Acesso em: 03 de fevereiro. 2012. doi: 10.4103/00195413.57280 .

CARTER, J.D. et al. Clinical and radiographic assessment of transforaminal lumbar interbody fusion using HEALOS collagenhydroxyapatite sponge with autologous bone marrow aspirate. Spine Journal, v.9, p.434-438, 2009. Disponível em: <http:/ /www.sciencedirect.com/science/article/pii/S152994300801 4393\#>. Acesso em: 05 de outubro. 2011. doi: 10.1016/ j.spinee.2008.11.004. 
CHRISTENSEN, F.B. et al. Interobserver and intraobserver agreement of radiograph interpretation with and without pedicle screw implants: the need for a detailed classification system in posterolateral spinal fusion. Spine, v.26, p.538-544, 2001. Disponível em: <http://journals.lww.com/spinejournal/pages/ articleviewer. aspx ?year $=2001 \&$ issue $=03010 \&$ article $=00018 \&$ type $=$ abstract $>$. Acesso em: 09 de abril. 2011.

COOK, S.D. et al. Low-intensity pulsed ultrasound improves spinal fusion. Spine Journal, v.1, p.246-254, 2001. Disponível em: <http://www.sciencedirect.com/science/article/ pii/S1529943001000869\#>. Acesso em: 12 de abril. 2011. doi: S1529-9430(01)00086-9.

COOK, S.D. et al. Comparison of methods for determining the presence and extent of anterior lumbar interbody fusion. Spine, v.29, n.10, p.1118-1123, 2004. Disponível em: <http:// ovidsp.tx.ovid.com/sp-3.8.0a/ovidweb.cgi?QS2>. Acesso em: 12 de abril. 2011. doi: 00007632-200405150-00013.

DEWEY, C.W. Neurologia de cães e gatos - Guia prático. São Paulo: Roca, 2006. 353p.

DRESPE, I.H. et al. Animal models for spinal fusion. Spine Journal, v.5, p.209-216, 2005. Disponível em: <http:// www.sciencedirect.com/science/article/pii/S15299430050 00847\#>. Acesso em: 12 de abril. 2011. doi: 10.1016/ j.spinee.2005.02.013.

FESTUGATTO, R. et al. Modificação da técnica de abordagem à articulação atlantoaxial sem a secção do músculo esternotireoideo. Ciência Rural, v.39, n.4, p.1239-1242, 2009. Disponível em: <http://www.scielo.br/pdf/cr/v39n4/ a148cr597.pdf >. Acesso em: 12 de abril. 2011. doi: doi.org/ 10.1590/S0103-8478200900500004.

FLEISS, J.L. Statistical methods for rates and proportions. New York, John Wiley \& Sons, 1973. 800p.

GUPTA, M.C. et al. Efficacy of mesenchymal stem cell enriched grafts in an ovine posterolateral lumbar spine model. Spine, v.32, n.7, p.720-726, 2007. Disponível em: <http:// www.ncbi.nlm.nih.gov/pubmed/17414903>. Acesso em: $14 \mathrm{de}$ abril. 2011. doi: 10.1097/01.brs.0000258863.40984.32 .

HERBERT, S. et al. Ortopedia e traumatologia: princípios e prática. 2.ed. Porto Alegre: Art. Méd., 1998. 1696p.

JESEREVICS, J. et al. Stabilisation of atlantoaxial subluxation in the dog through ventral arthrodesis. Schweiz Arch Tierheilk, v.150, p.69-76, 2008

LANDIS, J.R.; KOCH, G.G. The measurement of observer agreement for categorical data. Biometrics, v.33, n.1, p.159174, 1977. Disponível em: <http://www.jstor.org/stable/ 2529310>. Acesso em: 14 de maio. 2011.

LEE, T.C. et al. Application of extracorporeal shock wave treatment to enhance spinal fusion: a rabbit experiment. Surgical Neurology, v.70, p.129-134, 2008. Disponível em: $\langle$ http://www.sanuwave.com/epub/bone/bone_10.pdf $\rangle$. Acesso em: 18 de maio. 2011. doi: 10.1016/j.surneu.2007.05.050.

LIPPMAN, C.R. et al. Cervical spine fusion with bioabsorbable cages. Neurosurgery Focus, v.16, n.3, p.1-10, 2004. Disponível em: <http://www.ncbi.nlm.nih.gov/pubmed/ 15198492>. Acesso em: 18 de maio. 2011.
LORENZ, M.D.; KORNEGAY, J.N. Neurologia veterinária. 4.ed. São Paulo: Manole, 2006. 467p.

MARTINEZ, S.A.; WALKER, T. Bone grafts. Veterinary Clinics of North America: Small Animal Practice, v.29, n.5, p.1207-1219, 1999.

MAZZANTI, A. et al. Homoimplante ortotópico conservado, associado à terapia "soft laser" na reparação tenopatelar em cão. Ciência Rural, Santa Maria, v.34, n.2, p.429-437, 2004. Disponível em: <http://www.scielo.br/scielo.php?script=sci_arttext\&pid=S010384782004000200015>. Acesso em: 18 de maio. 2011. doi: http:// dx.doi.org/10.1590/S0103-84782004000200015.

MINAMIDE, D. et al. The effects of bone morphogenetic protein and basic fibroblast growth factor on cultured mesenchymal stem cells for spine fusion. Spine, v.32, n.10, p.1067-1071, 2007. Disponível em: <http://www.ncbi.nlm. nih.gov/pubmed/17471086>. Acesso em: 19 de maio. 2011. doi: 10.1097/01.brs.0000261626.32999.8a.

MING YEE, A.J. et al. Accuracy and interobserver agreement for determinations of rabbit posterolateral spinal fusion. Spine, v.29, n.12, p.1308-1313, 2004. Disponível em: <http:// www.ncbi.nlm.nih.gov/pubmed/15187630>. Acesso em: 19 de maio. 2011. doi: 10.1097/01.BRS.0000127184.43765.61.

OLBY, N.; PLATT, S. Canine and feline neurology. 3.ed. Inglaterra: BSVA, 2004. 350p.

O'LOUGHLIN, P.F. et al. Parathyroid hormone (1-34) augments spinal fusion, fusion mass volume, and fusion mass quality in a rabbit spinal fusion model. Spine, v.34, n.2, p.121130, 2009. Disponível em: <http://www.ncbi.nlm.nih.gov/ pubmed/19112335>. Acesso em: 19 de junho 2011. doi: 10.1097/ BRS.0b013e318191e687.

PIERMATTEI, D.L.; FLO, G.L. Manual de ortopedia e tratamento das fraturas dos pequenos animais. 3.ed. São Paulo: Manole, 1999. 896P.

PLATT, S.R. et al. A modified ventral fixation for surgical management of atlantoaxial subluxation in 19 dogs. Veterinary Surgery, v.33, p.349-354, 2004. Disponível em: <http:// onlinelibrary.wiley.com/doi/10.1111/j.1532-950X.2004. 04050. $\mathrm{x} /$ abstract ; jessionid $=37 \mathrm{~F} 0979$ CAA8947C6C5C 422 DE84F9BA5D.d02t04>. Acesso em: 23 de junho 2011. doi: 10.1111/j.1532-950X.2004.04050.x.

SANADA, J.T. et al. Análise histológica, radiográfica e do perfil de imunoglobulinas após implantação de enxerto de osso esponjoso bovino desmineralizado em bloco em músculo de ratos. Journal of Applied Oral Science, v.11, p.209-215, 2003. Disponível em: <http://www.scielo.br/scielo.php?pid=S1678-77572003000 300010\&script=sci_arttext $>$. Acesso em: 23 de junho 2011. doi: http://dx.doi.org/10.1590/S1678-77572003000300010.

SCHULZ, K.S. et al. Application of ventral pins and polymethylmethacrylate for the management of atlantoaxial instability: Results in nine dogs. Veterinary Surgery, v. 26, n. 4, p. 317-325, 1997.

SHARP, N.J.H.; WHEELER, S.J. Small animal spinal disorders. Diagnosis and surgery. 2.ed. Philadelphia: Elsevier Mosby. 2005. 380p. 
SHIRES, K. Instabilidade atlantoaxial. In: SLATTER, D. Manual de cirurgia de pequenos animais. 2.ed. São Paulo: Manole, 1998. V.1, cap.73, p.1261-1269.

SHORES, A.; TEPPER, L.C. A modified ventral approach to the atlantoaxial junction in the dog. Veterinary Surgery, v.36, p.765-770, 2007. Disponível em: <http://onlinelibrary.wiley.com/ doi/10.1111/j.1532-950X.2007.00334.x/pdf>. Acesso em: 28 de junho 2011. doi: 10.1111/j.1532-950X.2007.00334.x.

SILVA, R.B. et al. Avaliação da dor e morbidade local da retirada do enxerto ósseo da crista ilíaca para artrodese cervical anterior. Coluna, v.9, n.4, p.424-429, 2010. Disponível em: <http:// w w w. s c i e 1 o.b r / s c i e 1 o.ph p ? p id $=$ S 1808 18512010000400014\&script=sci_arttext $>$. Acesso em: 28 de junho 2011. doi: http://dx.doi.org/10.1590/S1808-18512010000400014.

SORJONEN, D.C.; SHIRES, P.K. Atlantoaxial instability: A ventral surgical technique for decompression, fixation, and fusion. Veterinary Surgery, v.10, p.22-29, 1981. Disponível em: <http://onlinelibrary.wiley.com/doi/10.1111/j.1532-
950X.1981.tb00625.x/abstract>. Acesso em: 28 de junho 2011. doi: 10.1111/j.1532-950X.1981.tb00625.x.

STEVENSON, S. Bone grafting. In: BOJRAB, M.J. et al. Current techniques in small animal surgery. 3.ed. Philadelphia: Lea \& Febiger, 1990. Cap.3, p.836-844.

THOMAS, W.B. et al. Surgical management of atlantoaxial subluxation in 23 dogs. Veterinary Surgery, v.20, n.6, p.409412, 1991.

VOLPON, J.B.; DA COSTA, R.M. Ensaio mecânico e uso clínico do enxerto homógeno processado. Revista Brasileira de Ortopedia, v.35, n.6, p.219-224, 2000.

WHEELER, D.L. et al. Efficacy of silicated calcium phosphate graft in posterolateral lumbar fusion in sheep. Spine Journal, v.7, p.308-317, 2007. Disponível em: <http://www.sciencedirect.com/ science/article/pii/S1529943006000143>. Acesso em: 28 de junho 2011. doi: 10.1016/j.spinee.2006.01.005. 